14. Dickinson, L. (1987). Self-instruction in Language Learning. Cambridge: Cambridge University Press, 200.

15. Holec, H. (1998). L'apprentissage auto-dirigé: une autre offre de formation. Le français dans le monde. Recherches et applications. Apprentissage et usage des langues dans le cadre européen. Juillet, 213-256.

Рекомендовано до публікації д-р пед. наук, професор Іваненко. В. К. Дата надходження рукопису 23.01.2015

Рощупкина Елена Анатольевна, кандидат педагогических наук, доцент, кафедра языковой подготовки Запорожский государственный медицинский университет, пр. Маяковского, 26, г. Запорожье, Украина, 69035

E-mail: cpklena@mail.ru

УДК 159.922.4:378.147-057.875-054.6-048.56

DOI: $10.15587 / 2313-8416.2015 .37396$

\title{
ЭТНОПСИХОЛОГИЧЕСКИЕ ОСОБЕННОСТИ ИНОСТРАННЫХ СТУДЕНТОВ И НАЦИОНАЛЬНЫЕ РАЗЛИЧИЯ ИХ ОБРАЗОВАТЕЛЬНЫХ СИСТЕМ
}

\author{
(C) Е. И. Гейченко, Л. И. Васецкая, В. Д. Хейлик \\ В статье описываются стратегии гармонизации довузовского когнитивного учебного опьта \\ иностранцев и лингводидактических технологий формирования коммуникативной компетенции в \\ условиях обучения языку в полинациональных группах в украинских вузах нефилологического профиля на \\ основе национально ориентированного подхода. Выделяются некоторые проблемы социокультурной \\ адаптации и роль в их нивелировании эффективных приёмов отработки речевых навыков и умений \\ Ключевые слова: региональные, культурные и ментальные особенности, альтернативные \\ технологические решения, этнопедагогика
}

The article deals with the issue of harmonization of pre-university cognitive experience of foreigners and linguodidactic technologies of communicative competence formations in the language learning in multinational groups in Ukrainian non-linguistic universities on the basis of nationally oriented approach. Some problems of social and cultural adaptation and role of effective methods of speech skills in their elimination are revealed

Keywords: regional, cultural and mental features, alternative technological solutions, ethnopedagogics

\section{1. Введение}

Современный учебный процесс убеждает в необходимости перехода от единообразия, излишней стандартизации образования, ведущего к консерватизму и схематизму, к многообразию, дифференциации и индивидуализации обучения.

Дифференцированное обучение русскому языку как иностранному может организовываться, во-первых, в зависимости от степени различий в содержании обучения (профилированное, вариатив ное, индивидуализированное) и, во-вторых, в зависимости от психологических особенностей обучаемых (интересов и склонностей, способностей и возможностей, индивидуальных качеств). Безусловно, эти два способа взаимопересекаются.

Опыт работы с иностранными студентами различных национальностей свидетельствует, что в методике преподавания РКИ должны учитываться их национальные (региональные, культурные, ментальные) психологические особенности, поскольку успешность или замедление процесса формирования навыков и умений всех видов речевой деятельности на иностранном языке напрямую зависит от уровня их сформированности на родном (или первом иностранном) языке и определяется индивидуальносубъективными сторонами процесса усвоения/овладения языковой и коммуникативной компетенциями, a также от влияния особенных и устойчивых национальных различий в системе образования.

Поэтому задача языковых кафедр представление иностранцам возможных альтернативных технологических решений в обучении всем видам речевой деятельности (ВРД), опирающихся на разные конструкты этого феномена как процесса.

Формирование у иностранных учащихся коммуникативной компетенции предполагает использование таких технологий обучения, которые обеспечивали бы моделирование процессов плодотворного аудиторного общения. Современная педагогическая стратегия, базирующаяся на коммуникативноличностном подходе, характери-зуется повышенным вниманием к таким актуальным проблемам, как гуманизация обучения, этнопеда-гогизация учебного процесса на основе исполь-зования национальнокультурных и социально-психологических особенностей иностранцев.

\section{2. Анализ литературных данных}

Вопросы использования особенностей этнокультурного фона в образовательном процессе рассматривались в работах М. Н. Вятютнева, О. Д. Митрофановой, Д. Дэвидсона, Е. И. Пассова, И. Е. Бобрышевой, А. В. Друзя, Н. Б. Крыловой, А. В. Рябоконя, В. Б. Манджиевой, Г. А. Палаткиной и др. 
Так, М. Н. Вятютнев, акцентируя внимание на наличии индивидуальных стилей усвоения, допускает возможность при подготовке учебных материалов рассматривать факторы, связанные с особенностями овладения русским языком учащимися различных национальных контингентов, а также сложившиеся в их лингводидактике традиции [1].

По мнению Е. И. Пассова, любая человеческая способность является синтезом врождённого и приобретённого в процессе индивидуального развития. Чтобы успешно обучать иностранным языкам, нужно уметь учитывать, замерять уровень способностей учащихся и постоянно развивать их. Ученик, по мнению автора, часто не выполняет какое-либо задание только потому, что он не знает, как этого достичь, не владеет алгоритмом реализации поставленной цели [2], что даёт основание А. В. Рябоконю говорить об «априорном коммуника-тивном опыте» и путях его «прилаживания» к новым учебным условиям [3].

\section{3. Постановка проблемы}

Таким образом, весьма важным для нас видится учёт как этнокультурных расхождений (определение точек соприкосновения/различия между принятой у нас лингводидактической моделью и своеобразием учебно-познавательной деятельности иностранных учащихся различных регионов), так и преодоления определённой биполярности между европейской (в т. ч. американской) и характерными для стран Ближнего и Дальнего Востока, Латинской Америки, Африки и Юго-Восточной Азии специфическими национально-методическими традициями обучения языкам. Это и определило актуальность данной работы.

Целью статьи является анализ национальных различий в образовательных и методических системах ряда стран, рассмотрение вопроса о переориентации методических традиций перечи-сленных регионов на устоявшиеся в нашей образовательной парадигме учебные стратегии формирования коммуникативной компетенции на основе этноориентированной модели обучения РКИ.

\section{4. Теоретическая база национально} дифференцированного обучения языку в условиях иноязычной среды

Может показаться, что процесс социализации иностранцев завершается на подготовительном факультете, однако психолого-культурная адаптация к новым социально-педагогическим условиям (особенно в рамках полноценного вузовского обучения) у представителей разных регионов неодинакова. К началу обучения на первом курсе низким тревожным состоянием характеризуются студенты из Марокко, Сирии, Ливана, а граждане из Палестины, Иордании продолжают сохранять состояние беспокойства, представители Египта, Нигерии, Ганы - настороженности, эквадорские студенты - подавленности, внутренней замкнутости и выжидающей пассивности.
Многолетние наблюдения над контингентом приезжающих на учёбу в украинские университеты иностранцев позволили нам выделить наиболее типичные черты их характеров. В общем виде можно отметить следующие: стремление к метафоричности и образности в речи арабских студентов, что отличает их многословием, эмоциональностью и экспрессивностью, в отличие от студентов из стран центральной Африки (Нигерия, Кения, Танзания, Конго, Замбия и др.), которые излишне прагматичны - как в быту, так и в речи - сдержанны и максимально конкретны. И, что немаловажно, дистанцированы по отношению как к ближне-, так и дальневосточным студентам. Следует заметить, что и арабоговорящие граждане существенно разнятся в силу исторических реалий. Так, французская (а значит, европейская) образовательная система неоднозначно сказывается на культурно-психологических и лингвистических характерис-тиках представителей стран Магриба (Марокко, Тунис, Алжир и др.), в отличие от «сугубо восточ-ных» сирийцев, ливанцев, египтян и иракцев [4].

Уместно в этой связи и замечание суданского исследователя А. Х. Сумейи о том, что «арабоязычные социумы стран Магриба и Судан являются достаточно далекими по своим историческим, социально-экономическим, политическим, культурно-психологическим особенностям. Судан - это не «чисто арабская» страна. Для неё характерен определённый исторически сложившийся дуализм. Так, в силу различных причин, наиболее близкой страной арабского мира для Судана является Египет, при этом наибольшее «тяготение» существует у Судана к центральноафриканским странам. Даже из этих коротких замечаний можно понять, насколько суданцы отличаются от жителей стран, расположенных на побережье Средиземного моря» $[5,13]$.

Учебная манера ближневосточных учащихся описана в работе Т. Дадли-Эванса и Дж. Свейлса. Они высказывают тезис о том, что различия в системах образования (европейской и арабской) есть не что иное как «разница поколений», так как методические постулаты и приёмы, широко применяемые в этом регионе сегодня, часто очень напоминают те, что были характерны для Запада полувековой давности: непререкаемый авторитет преподавателя, упор на усвоение знаний в форме, в которой они преподносились, стиль письма в традициях беллетристики и т. д.

Различаются образовательные системы в релевантности к религии. С одной стороны, секуляризм (межрелигиозная толерантность) западного образования, с другой - исламизированная восточная образовательная традиция, лежащая в основе подготовки к экзаменам. В частности, для Судана характерно специфическое механическое рутинное запоминание - дословный пересказ прочитанного вслух самому себе (идя из точки А до точки Б, студент вслух читает порцию материала, а возвращаясь обратно, воспроизводит прочитанное по памяти). Вторым способом запоминания является 
трудоёмкий процесс многократного переписывания материала. Как резюмируют авторы, знания, накопленные таким образом, не всегда воспроизводятся при селективном припоминании для приведения нужной в данный момент аргументации на экзамене, чаще всего отсутствует так называемая «ассоциативная память» [6].

В отличие от арабов несколько пассивны в выражении своих мыслей представители ЮгоВосточной Азии (Китай, Малайзия, Таиланд, Вьетнам, северные штаты Индии и др.), для которых характерна боязнь «потерять лицо», что способствовало укоренению коллективного заучивания на основе зрительной наглядности с опорой на текст, хорового произношения и письменной фиксации. В соседних же Кампучии и Лаосе дети воспитывались на устной традиции восприятия как сказок, так и более крупных письменных произведений: назидательных сочинений, романов и религиозной литературы, что в определённой мере объясняет отсутствие навыков чтения.

Р. Хоукей и Ч. Накорнчай на контрастивной основе через призму изучения иностранного языка описали особенности тайской школьной системы. Культурный профиль контингента составлен из трёх отдельных групп факторов: образовательнометодических (состав групп из 35 человек и более; привычка к общеклассному обучению, хоровым ответам; отсутствие индивидуальных видов работ, семинарской или наставнической работы; ориентация сугубо на учебник, что принижает авторитет и методический уровень преподавателя, сдерживает развитие критических и креативных способностей учащихся; въевшаяся традиция натаскивания на ответы к тестам и экзаменам на основе содержания учебника; дальнейшая профессиональная дифференциация на основе количества баллов и др.), образовательно-культурных (руководящая и контролирующая роль преподавателя на всех этапах обучения; привычка «учиться из ложечки», выполнять только пассивную роль в учебном процессе прямое и безоговорочное усвоение презентованных преподавателем знаний, что не способствует формированию у учащихся уверенности в себе и самомотивации; механическое и рутинное учение как следствие перечисленных нюансов) и общих характерных черт (невозмутимость и спокойный нрав, традиция сдерживания чувств, тенденция «сохранения лица», основанная на отсутствии поводов для критики, воспринимаемой как оскорбление и др.) [7].

В исследовании П.Харвея проанализированы китайские «методы учения» называемые в тексте также и «учебными стратегиями» (learning strategies) и характеризуются они следующими чертами: концентрация на интенсивном чтении как основе изучения языка, грамматической структуре языка в ущерб коммуникативно значимым аспектам речевой деятельности, механической зубрёжкой как основой усвоения знаний, широким использованием перевода как стратегии и учения, и обучения. По мнению исследователя, тяготение к печатному слову приводит, в основном, к выработке «экстенсивных навыков учения» (extensive learning skills) [8].

В этой связи отметим, что студентов с европейскими традициями изучения иностранных языков отличают: контекстуальная догадка, вербальное ассоциирование, анализ (членение, выявление взаимосвязей между частями, осознание принципов организации частей в целое; словообразовательный, контрастивный, языковой, семантический, этимологический текстовой анализ), формально-логическое абстрагирование (категоризация, классификация, концептуализация) и др. [9].

Переориентация же китайских студентов на новые учебные стратегии и технологии, на наш взгляд, должна происходить на основе методически целесообразного использования лингводидактических традиций Китая. Данные образовательные традиции характеризуются приоритетом чтения, письма, грамматики, накопления словаря, системного контроля. Эффективная трансмиссия названной методической модели обучения в отечественную возможна путем логичного и последовательного наращивания новых приемов обучения и постепенного замещения учебно-познавательных приемов, присущих системе образования в Китае, методическими и педагогическими инновациями.

В целях поддержания мотивации китайских учащихся в овладении РКИ и оптимизации обучения важно опираться на развитые и устойчивые стороны этнопсихики: высокий уровень мнемических способностей (запоминание, классифицирование), развитую интуицию, зрительный канал восприятия и зрительно-двигательный тип памяти, активное использование аналогии, контекстуальной догадки и др. [10].

Анализируя сказанное с позиций этнопедагогики, важно заметить, что преподавателю на данном этапе необходимо найти и использовать приемы и методы обучения, разрушающие возникшие преграды для взаимодействия. И тут особое значение приобретает метод сотрудничества. Возникновение и развитие сотворчества в данной ситуации зависит от ролевых позиций, занимаемых каждым из участников. Проявляется явная обусловленность этих позиций и схем взаимоотношений в системе «преподаватель - иностранный студент» этнопсихологическими особенностями студентов [11].

Студенты Ближнего Востока раньше других выявляют способность к активному, плодотворному творческому диалогу. Но при условии, что они, вопервых, будут ощущать себя равными по ценностноличностным параметрам преподавателю, во-вторых, будут видеть его неподдельный интерес к себе как личности.

Африканские (англоговорящие) студенты идут на диалог с преподавателем (в форме сотрудничества) в ситуациях, когда их воспринимают как индивидуальность, проявление ими неуступчивости не вызывает у преподавателя раздражения, нетерпимости к их позиции и желания поучать, когда преподаватель первый проявляет готовность пойти на компромисс. 
Отличается от уже описанных взаимоотношений в форме «ролевых равновесий» схема позиций в творческом учебном сотрудничестве «преподаватель - студенты Юго-Восточной Азии (Индия, Бангладеш, Шри-Ланка)». Представители этого региона не нарушают раз и навсегда сформированных ранее отношений к преподавателю, как к фигуре более значимой в этом диалогическом взаимодействии, чем они сами, и отводят ей главное место - лидера и авторитета.

Важным моментом во взаимоотношениях преподавателя с иностранным студентом является акт помощи. Внешне одинаковые акты помощи отличаются внутренним содержанием: в одном случае, это проявление заботы, сочувствия, желания помочь, потому что в этом нуждаются, в другом вызваны желанием инструктировать, поучать, наставлять, проявлять превосходство, власть. Второй вариант помощи необходимо полностью исключить, т. к. он приведет к невозможности и нежеланию со стороны другого участника взаимодействия продолжать сотрудничество.

В учебном процессе отношение студента к помощи со стороны преподавателя дифференцировано в зависимости не только от этнопсихологических особенностей студента, но и от его ценностно-мотивационных установок.

В процессе обучения высокой потребностью в помощи преподавателя отличаются арабские и эквадорские студенты. И не только в ситуациях, когда она им необходима, а и потому, что, например, арабские студенты оценивают оказание помощи, как особое к ним расположение, повышение их значимости в глазах одногруппников. Студенты из Эквадора нуждаются в помощи-опёке, им необходим постоянный контроль со стороны преподавателя для завершения начатой роботы и получения адекватных их способностям результатов. К примеру, студенты из Нигерии с особой обеспокоенностью относятся к сохранению своей репутации «автономных» учащихся - преподавателю не стоит навязывать им лишний раз свою помощь, а необходимо поддержать их сознательность и усердность. При этом благоприятствующим фактором является создание учебно-проблемных или психолого-педагогических ситуаций, разрешая которые, нигерийские студенты начинают испытывать уверенность в своих силах. Это способствует самоактуализации, приобретению психологической (личностной) свободы.

Индийские студенты акт помощи воспринимают благоприятно. Этот акт активизирует их учебно-познавательную деятельность, а также усиливает потребность в сотрудничестве с преподавателем, если помощь будет предложена не отдельно взятому студенту, не отдельной личности, а как бы всему коллективу или его части. Использование данной тактики в среде студентов из Юго-Восточной Азии приводит к активизации и раскрытию интеллектуального багажа и учебно- познавательных способностей зачастую молчаливых, замкнутых или так называемых «неспособных» к освоению иностранного языка.

Общение в системе «преподаватель иностранный студент» в процессе обучения не сводится только к обмену информацией, а предполагает и оценивание ее содержания студентами. При этом важным моментом является вовлечение студентов-иностранцев во взаимодействие, обусловленное эмоциональной активностью личности. Подобная практика осуществима, если у участников педагогического взаимодействия создан определенный «эмпатийный настрой». Однако отметим, что значение эмоционального фактора при данном взаимодействии неодинаково для разных контингентов иностранных граждан. Студенты из Африки характеризуются интенсивной внутренней жизнью, но у них трудно вызвать эмоциональный всплеск, с его последующей экспликацией. Представители Ближнего Востока быстрее проявляют готовность к психолого-эмоциональному контакту, но при этом он часто носит у них внешний характер проявления, не затрагивающий и не изменяющий их внутренний мир.

Педагогическое взаимодействие, основанное на эмоциональном настрое, не должно быть подвержено «форсированию», а должно стать внутренне необходимым и социально значимым. Преподавателю важно сохранить его привлекательность и силу воздействия. При этом стойкость возникших взаимоотношений сохранится, если иностранный студент будет продолжать ощущать себя личностью, чья эмоциональная, внутренняя жизнь интересна для партнера по педагогическому взаимодействию.

Акценты в отношениях «преподаватель иностранный студент» расставлены при названном выше взаимодействии следующим образом: отправная точка взаимоотношений - личность субъекта, центр - сопереживание, выражение собственных положительных эмоций [3, 193].

Отметим, что учет этнопедагогических и этнопсихологических аспектов обучения иностранцев - это, прежде всего, бережное отношение к личности иностранного студента, желание преподавателя, несмотря на все трудности, сложности, не разрушить индивидуальность студе-нта, а сохранить и скорректировать его культурно-ценностную базу, эмоционально-поведенческую деятельность, чтобы у него появилась возможность адекватной самооценки и не возникла потребность в защите своих этнокультурных ценностей.

Стадиальность введения речевых единиц, чёткая алгоритмизация учебных действий с учётом этнокультурного потенциала студентов подводит преподавателя к постепенной унификации содержания и средств обучения. Таким образом, создаётся основа для формирования в дальнейшем на продвинутом этапе у учащихся этой категории 
профессионально ориентированной коммуникативной компетенции, что в достаточной степени соотносится с их речевыми потребностями в условиях вузовских реалий.

\section{5. Выводы}

Итак, мы полагаем, что в процессе усвоения русского языка как иностранного должна наблюдаться взаимосвязь лингвистических, методи-ческих и психолингвистических факторов, причем важная теоретическая и практическая роль должна отводиться учету этнопсихологических особенностей иностранных студентов в контексте их национальных моделей обучения. Это требует разработки более широкой методической стратегии и системы обучения, отвечающей дифференцированным коммуникативным потребностям иностранцев, а также учебных пособий, целенаправленно учитывающих будущую профессиональную деятель-ность контингента, его культурно-психологические национальные особенности и другие специфические условия обучения в неязыковом вузе Украины.

\section{Литература}

1. Вятютнев, М. Н. Теория учебника русского языка как иностранного (методические основы) [Текст] / М. Н. Вятютнев. - М.: Рус. яз., 1990. - 144 с.

2. Пассов, Е. И. Основы коммуникативной методики обучения иноязычному общению [Текст] / Е. И. Пассов. - М.: Рус. яз., 1989. - 276 с.

3. Рябоконь, А. В. О типологии индивидуальных стилей учебной деятельности и их учёте при конструировании учебника иностранного языка [Электронный ресурс] / А. В. Рябоконь // Вестник ЦМО МГУ. - 1998. - № 1. - Режим доступа : www.cie.ru/vestnik/archiva/n1/p1/w02/

4. Хейлик, В. Д. Корреляция национальных методических традиций и стратегий обучения русскому языку иностранных студентов в вузах Украины [Текст] / В. Д. Хейлик // Учёные записки ТНУ им. В.И.Вернадского. Серия «Филология. Социальные коммуникации». - 2012. Т. 25 (64), № 1, Ч. 1. - С. 182-187.

5. Сумейя, А. Х. Теоретические основы создания программы и национально ориентированного учебника для начального этапа обучения русскому языку в Судане [Текст]: дис. ... канд. пед. наук: 13.00.02 / А. Х. Сумейя. М., 1998. - $170 \mathrm{c.}$

6. Dadley-Evans, T. Stady modes and students from the Middle East [Text] / T. Dadley-Evans, J. Swales // ELT documents. - 1980. - Vol. 109. - P. 91-103.

7. Hawkey, R. Thai students studying [Text] / R. Hawkey, Ch. Nakornchai // TLT documents. - 1980. Vol. 109. - P. 70-78.

8. Harvey, P. A. Lesson to be learned: Chinese approaches to language learning [Text] / P. Harvey // ELT Journal. - 1985. - Vol. 39, Issue 3. - P. 183-186. doi: $10.1093 /$ elt/39.3.183

9. Бобрышева, И. Е. Модель коррекции заданий и упражнений с учётом культурно-типологичеких стилей учебно-познавательной деятельности [Текст] / И. Е. Бобрышева // Русский язык за рубежом. - 2004. № 1. - С. 38-48.

10. Чжао, Ю. Лингводидактические основы этноориентированного обучения русскому языку и тестирования на примере китайских учащихся [Текст]: дис. ...канд. пед. наук: 13.00.02 / Ю. Чжао. - М., 2008. $297 \mathrm{c}$.

11. Васецкая, Л. И. Особенности педагогического взаимодействия системы «преподаватель - иностранный студент» на продвинутом этапе [Текст] / Л. И. Васецкая // Педагогіка і психологія формування творчої особистості: проблеми і пошуки : зб. наук. праць. - 2011. - Вип. 20. C. 187-191.

12. Васецкая, Л. И. Этнопедагогические и этнопсихологические аспекты обучения иностранных студентов [Текст]: матер. III межд. науч.-прак. конф. / Л. И. Васецкая // Актуальные проблемы преподавания русского языка как иностранного в вузе. - М., 2014. - С. 190-195.

13. Митрофанова, О. Д. Функционирование русского языка: методический аспект [Текст] / О. Д. Митрофанова // Русский язык за рубежом. - 1990.№ 2. - С. 23-26.

\section{References}

1. Vatutnev, M. N. (1990). Teoria uchebnika russkogo yazika kak inostranogo.Moscow, 144.

2. Passov, E. I. (1989). Osnovi kommunikativnoy metodiki obucheniya inoyazichnomu obcheniyu. Moscow, 276.

3. Rayabokon, A. B. (1998). O tipoligii individualnih stiley uchebnoy deyatelnosti $\mathrm{i}$ ih uchete pri konstruirovanii uchebnika inostrannogo uazika. Vestnik TsMO MGU, 1. Available at : www.cie.ru/vestnik/archiva/n1/p1/w02/

4. Kheylik, V. D. (2012). Korelyaciya nacionalnih metodicheskih tradiciyi i strategiy obucheniya russkomu yaziku inostranih studentov v vuzah Ukraini. Uchebniye zapiski TNU im. V. I. Vernadskogo, 25 (1), 182-187.

5. Sumeya, A. H. (1998). Teoreticheskiye osnovi sozdaniya programi i nacionalno orientirovanogo uchebnika dlya nachalnogo etapa obucheniya russkomu yaziku v Sudane. Moscow, 170.

6. Dadley-Evans, T., Swales, J. (1980). Stady modes and students from the Middle East. ELT documents, 109, 91-103.

7. Hawkey, R., Nakornchai, Ch. (1980). Thai students studying. TLT documents, 109, 70-78.

8. Harvey, P. A. (1985). Lesson to be learned: Chinese approaches to language learning. 39 (3), 183-186. doi: 10.1093/elt/39.3.183

9. Bobrisheva, I. E. (2004). Model korekciizadaniyi i uprajneniyi $\mathrm{s}$ uchetom kulturno-tipologicheskih stiley i uchebno-poznovatelnoyi deyatelnosti . Russkiy iyazik za rubejom, 1, 38-48.

10. Chzhao, Y. (2008). Lingvodidakticheskiye osnovi etnoorientirovanogo obucheniya russkomu yasiku i testirovaniya naprimere kitayiskih uchashihsya. Moscow, 297.

11. Vasetskaya, L. I. (2011). Osobennosti pedagogicheskogo vzaimodeystviya sistemi “ prepodavatelinostraniy student" na prodvinutom etape. Pedagogyka i psichologiya formuvanya tvorchoy osobistosty : problemi i poshuki [Sbornik nauchn. trudov]. Kiev, 187-191. 
12. Vasetskaya, L. I. (2014). Etno-pedagogicheskie i etno-psihologicheskie aspekti obucheniya inostranih studentov. Aktualnie problem prepodavaniya russkogo yazika kak inostranogo v vuze. Moscow, 190-195.
13. Mitrofanova, O. D. (1990). Funkcionirovaniye russkogo yazika: metodicheskiyi aspect. Russkiy yazik za rubejom, 2, 23-26.

Рекомендовано до публікації д-р пед. наук, професором Іваненко. В. К. Дата надходження рукопису 28.01.2015

Гейченко Екатерина Ивановна, кандидат педагогических наук, заведующий кафедрой, кафедра языковой подготовки, доцент, Запорожский государственный медицинский университет, пр. Маяковского, 35, г. Запорожье, Украина, 69035

Васецкая Лариса Ивановна, кандидат педагогических наук, доцент, кафедра языковой подготовки, Запорожский государственный медицинский университет, пр. Маяковского, 35, г. Запорожье, Украина, 69000

E-mail: larysa_v@mail.ru

Хейлик Владимир Дмитриевич, кандидат педагогических наук, доцент, кафедра языковой подготовки, Запорожский государственный медицинский университет, пр. Маяковского, 35, г. Запорожье, Украина, 69000

E-mail: vdh1957@mail.ru 